\title{
Pan-genome analysis of the emerging foodborne pathogen Cronobacter spp. suggests a species- level bidirectional divergence driven by niche adaptation
}

Christopher J Grim,2, Michael L Kotewicz , Karen A Power ${ }^{3}$, Gopal Gopinath', Augusto A Franco ${ }^{1}$, Karen G Jarvis ${ }^{1}$, Qiong Q Yan ${ }^{3}$, Scott A Jackson ${ }^{1}$, Venugopal Sathyamoorthy ${ }^{1}$, Lan $\mathrm{Hu}^{1,2}$, Franco Pagotto ${ }^{4}$, Carol Iversen ${ }^{5}$, Angelika Lehner ${ }^{6}$, Roger Stephan ${ }^{6}$, Séamus Fanning ${ }^{3}$ and Ben D Tall ${ }^{1 *}$

\begin{abstract}
Background: Members of the genus Cronobacter are causes of rare but severe illness in neonates and preterm infants following the ingestion of contaminated infant formula. Seven species have been described and two of the species genomes were subsequently published. In this study, we performed comparative genomics on eight strains of Cronobacter, including six that we sequenced (representing six of the seven species) and two previously published, closed genomes.

Results: We identified and characterized the features associated with the core and pan genome of the genus Cronobacter in an attempt to understand the evolution of these bacteria and the genetic content of each species. We identified 84 genomic regions that are present in two or more Cronobacter genomes, along with 45 unique genomic regions. Many potentially horizontally transferred genes, such as lysogenic prophages, were also identified. Most notable among these were several type six secretion system gene clusters, transposons that carried tellurium, copper and/or silver resistance genes, and a novel integrative conjugative element.

Conclusions: Cronobacter have diverged into two clusters, one consisting of C. dublinensis and C. muytjensii (CdubCmuy) and the other comprised of C. sakazakii, C. malonaticus, C. universalis, and C. turicensis, (Csak-Cmal-Cuni-Ctur) from the most recent common ancestral species. While several genetic determinants for plant-association and human virulence could be found in the core genome of Cronobacter, the four Cdub-Cmuy clade genomes contained several accessory genomic regions important for survival in a plant-associated environmental niche, while the Csak-Cmal-Cuni-Ctur clade genomes harbored numerous virulence-related genetic traits.
\end{abstract}

\section{Background}

Cronobacter is a newly described genus that includes opportunistic pathogens formerly classified as Enterobacter sakazakii [1]. E. sakazakii was first described by Farmer et al. [2], using DNA-DNA hybridization studies and phenotyping to reclassify a group of yellow-pigmented Enterobacter cloacae isolates attributed to cases of neonatal meningitis [3] into 15 phenotypically distinct biogroups. A $16^{\text {th }}$ biogroup was later described [4].

\footnotetext{
* Correspondence: ben.tall@fda.hhs.gov

'CFSAN, FDA, Laurel, USA

Full list of author information is available at the end of the article
}

Although E. sakazakii was synonymous with the original single species epithet, Iversen et al. [1], using a polyphasic approach based on extensive genotypic and phenotypic criteria, reclassified strains of this diverse species within the novel genus, Cronobacter. Originally, the genus contained six recognized species, C. sakazakii (Csak, biogroups 1-4, 7, 8, 11, and 13), C. malonaticus (Cmal, biogroups 5, 9, and 14), C. muytjensii (Cmuy, biogroup 15), C. turicensis (Ctur, biogroup 16), $C$. dublinensis, subsp. dublinensis, lausannensis, and lactaridi (biogroups 12, Cdubdub, 10, Cdublau and 6, Cdublact, respectively) and $C$. genomospecies 1 . Joseph

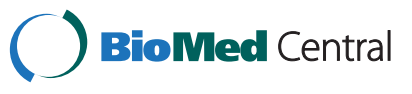


et al. [5] have updated this taxonomy by designating members assigned to the genomospecies group 1 as $C$. universalis (Cuni, biotype 16c) and identifying a new species, $C$. condimenti, based on a single known strain using a seven gene multi-locus sequence typing (MLST) scheme.

Cronobacter have been primarily associated with infections in infants, but recent reports have highlighted the risk posed to immune compromised adults, particularly the elderly [6,7]. Cronobacter have been recovered from a wide variety of foods, including powdered infant formula (PIF), follow-on formulas, weaning foods, milk and sodium caseinate powders, rice seed, dried herbs, teas, and spices, spiced meats, dried flour or meal (corn, soy, potato, wheat, and rice), dried infant and adult cereals, dried vegetables, grains, tofu, powdered ice tea, mixed salad vegetables, tomato harvesting bins, chocolate, candied cough drops, and pastas [8-12]. Nevertheless, PIF remains epidemiologically linked to outbreaks of neonatal and infantile meningitis, and Cronobacter are routinely isolated from household PIF preparation equipment, including blenders and spoons. Although PIF is regarded as an important source of this pathogen, the main reservoir for Cronobacter seems to be the environment [13].

Cronobacter are capable of surviving and persisting in low-water environments [8], owing to their distribution in dry food goods. Although the exact genetic determinant remains to be identified, Breeuwer et al. reported that intracellular accumulation of trehalose, among other features, prevents protein denaturation and membrane fusion and these may contribute to the desiccation-resistant properties of the bacterium [14,15]. The expression of an exopolysaccharide composed of cellulose may also be required [16]. Thermoresistance of Cronobacter has also been reported [14,17]. Proteins unique to thermotolerant Cronobacter strains have been identified by liquid chromatography and mass spectrometry; for example, a protein, Mfla_1165, which is a homologue of a hypothetical protein from the ther-motolerant bacterium Methylobacillus flagellatus KT [18]. Recently, an 18-kb region containing 22 open reading frames that are up-regulated under heat adaptation growth conditions has also been reported [19]. The major feature of the region is a cluster of conserved genes, which have significant homology to proteins involved in bacterial stress responses, including heat, oxidation, and acid.

Previously, Kucerova et al. [20] reported on the genome sequence of C. sakazakii ATCC BAA-894, which was isolated from a PIF product that was used in a neonatal intensive care unit and which gave rise to an outbreak in 2001 in Tennessee, USA. In an attempt to further determine virulence factors and mechanisms of pathogenicity in this bacterium, the genome of $C$. turicensis z3032, cultured from the blood of one child with meningitis [21] was sequenced [22]. In this paper, we describe the genomes of the type strains of Cronobacter dublinensis subsp. dublinensis, Cronobacter dublinensis subsp. lactaridi, Cronobacter dublinensis subsp. lausannensis, Cronobacter malonaticus, Cronobacter muytjensii, and Cronobacter universalis. Comparative genomics was performed on these six genomes, as well as two previously published, closed genomes of Cronobacter. We identified and characterized the features associated with the core and pan genome of this bacterial genus in an attempt to understand the evolution of these organisms and the genetic content of each species.

\section{Results}

\section{General features of sequenced Cronobacter genomes}

Whole genome sequencing of six species type strains of Cronobacter was performed (Table 1). Each genome analyzed in this study contained a single chromosome and a large repFIB plasmid, similar to Csak BAA-894 (pESA3) and Ctur z30232 (pCTU1), except the genome of $C$. muytjensii ATCC 51329. Previously, Franco and $\mathrm{Hu}$ et al. [23] reported that only $75 \%$ of strains of $C$. muytjensii harbored this plasmid, while the incidence of this plasmid in other Cronobacter spp. is $99 \%$. The G + C\% content of each genome ranged from 55 to $57 \%$ (Table 1). Each of the six draft genomes contained seven ribosomal RNA operons, as inferred from comparative genomics with Csak BAA-894 and Ctur z3032 (Table 1).

\section{Whole genome phylogeny and Cronobacter taxonomy}

To confirm the taxonomic standing of Cronobacter genus novum and species [1], genome scale analyses based on nucleotide sequence were performed. Average nucleotide identity (ANI) has emerged as one of the predominant genomics alternatives to DNA-DNA hybridization. The pairwise ANI values between all Cronobacter genomes used in this study support the current proposed species and subspecies classification of Cronobacter (Table 2). Although pairwise ANI values provide a benchmark of divergence (or similarity) between two genomes, evolutionary relationships between more than two genomes cannot be inferred from this analysis. Therefore, a genome scale phylogenetic analysis was performed on all eight Cronobacter genomes (Figure 1). This analysis reveals that extant Cronobacter species have diverged into two clusters, Cdub-Cmuy and CsakCmal-Cuni-Ctur, from the most recent shared ancestral species. The Cdub-Cmuy clade evolved as a monophyletic clade for much of its evolutionary history before diverging into two species. However, we expect the reconstruction of this evolutionary history to change significantly as new species that fall within this clade are identified; for example, C. condimenti [5]. In contrast, the other four species evolved as four distinct 
Table 1 General features of genomes used in this study

\begin{tabular}{|c|c|c|c|c|c|c|c|c|}
\hline Strain & $\begin{array}{l}\text { C. malonaticus } \\
\text { LMG } 23826\end{array}$ & $\begin{array}{l}\text { C. dub. } \\
\text { dublinensis } \\
\text { LMG } 23823\end{array}$ & $\begin{array}{l}\text { C. dub. } \\
\text { lausannensis } \\
\text { LMG } 23824\end{array}$ & $\begin{array}{l}\text { C. dub. } \\
\text { lactaridi } \\
\text { LMG } 23825\end{array}$ & $\begin{array}{l}\text { C. muytjensii } \\
\text { ATCC } 51329\end{array}$ & $\begin{array}{l}\text { C. universalis } \\
\text { NCTC } 9529\end{array}$ & $\begin{array}{l}\text { C. sakazakii } \\
\text { ATCC } \\
\text { BAA-894 }^{\text {a }}\end{array}$ & $\begin{array}{l}\text { C. turicensis } \\
{\mathrm{z} 3032^{\mathrm{a}}}\end{array}$ \\
\hline $\begin{array}{l}\text { Contigs/ } \\
\text { chromosomes }\end{array}$ & 69 & 41 & 105 & 96 & 32 & 16 & $\begin{array}{l}1+2 \\
\text { plasmids }\end{array}$ & $\begin{array}{l}1+3 \\
\text { plasmids }\end{array}$ \\
\hline $\begin{array}{l}\text { Mean contig } \\
\text { length }\end{array}$ & 64,056 & 113,291 & 43,937 & 46,393 & 136,123 & 274,265 & N/A & N/A \\
\hline Scaffolds & 4 & 14 & 15 & 10 & 4 & 8 & N/A & N/A \\
\hline $\begin{array}{l}\text { Mean sequence } \\
\text { gap length }\end{array}$ & 297 & 246 & 692 & 98 & 285 & 166 & $\mathrm{~N} / \mathrm{A}$ & N/A \\
\hline Genome size (bp) & $4,419,871$ & $4,644,913$ & $4,613,339$ & $4,453,746$ & $4,355,922$ & $4,388,239$ & $4,530,777$ & $4,599,092$ \\
\hline CDS & 4,041 & 4,172 & 4,123 & 4,077 & 3,973 & 3,977 & 4,211 & 4,296 \\
\hline $\mathrm{G}+\mathrm{C} \%$ & 54.99 & 56.16 & 56.84 & 56.87 & 56.17 & 55.79 & 56.7 & 57.2 \\
\hline $\begin{array}{l}\text { Coverage of } \\
\text { contigs }\end{array}$ & 15.33 & 20.28 & 13.8 & 14.63 & 17.36 & 25.38 & N/A & N/A \\
\hline tRNAs & 79 & 85 & 92 & 86 & 81 & 89 & 82 & 86 \\
\hline rRNA operons & 7 & 7 & 7 & 7 & 7 & 7 & 7 & 7 \\
\hline
\end{tabular}

${ }^{a}$ C. sakazakii strain BAA-894 and C. turicensis strain z3032 were previously sequenced and are considered to be closed reference genomes [20,22].

monophyletic lineages. The phylogenetic tree is, again, in good agreement with the current proposed taxonomy of Cronobacter [1], as well as recent proposed Cronobacter phylogenies derived from MLST [24] and sequence of the $r p o B$ gene $[25,26]$, although more resolving than $r p o B$ sequence for Csak-Cmal [27], and $\operatorname{rpoA}[28]$.

\section{Cronobacter core genome}

A Cronobacter core genome of orthologous, shared genes was determined for the eight strains analyzed in this study. The chromosome of each of the six type strains of Cronobacter consists of approximately 4,000 CDS (Table 1). Of this number, we determined that 3,160 CDS comprise the core genome of Cronobacter (Additional file 1: Table S1). Previously, Kucerova et al. [20] reported a core genome of 1,899 gene sequences, among five species using microarray hybridization based on the genome of Csak BAA-894; C. universalis was not included.
Among the genes comprising the core genome of Cronobacter, we found several genetic determinants that are experimentally-linked to phenotypic traits, such as reduction of nitrate, utilization of D-mannose, Dmannitol, sucrose, L-arabinose, cellobiose, and D-xylose (Additional file 1: Table S1), which have been previously reported by Iversen et al. [1] as biochemical traits of the genus as determined by phenotypic microarray. Additionally, we found genes, gene clusters or operons responsible for the following characteristics in the Cronobacter core genome: utilization of fructoselysine, psicoselysine, isomaltulose (palatinose), N-acetylglucosamine (nag), N-acetylmannosamine, and 2-ketogluconate; a carotenoid pigmentation cluster homologous to Pantoea spp., type IV pili (TFP), $\sigma$ chaperone/usher (CU) fimbriae, three $\gamma 1 \mathrm{CU}$ fimbriae, enterobactin siderophore gene clusters, ferric hydroxymate transporter, several ferric iron receptors, and two ferrous iron transporters [29], histidine transporter, yeh osmoprotectant transporter, zinc transporter, albicidin resistance protein coding gene, macrolide-specific ABCtype efflux pump and several putative multidrug resistance

Table 2 Average nucleotide identity (ANI) values for eight Cronobacter genomes

\begin{tabular}{|c|c|c|c|c|c|c|c|c|}
\hline ANI & BAA-894 & LMG 23825 & LMG 23823 & NCTC 9529 & 51329 & LMG 23826 & LMG 23824 & z3032 \\
\hline Csak ATCC BAA-894 & - & 88.59 & 88.43 & 93.28 & 88.57 & 94.61 & 88.57 & 91.85 \\
\hline Cdublac LMG 23825 & 88.57 & - & 97.24 & 89.21 & 91.94 & 88.77 & 98.36 & 88.81 \\
\hline Cdubdub LMG 23823 & 88.44 & $97.22^{a}$ & - & 88.97 & 91.65 & 88.54 & 97.29 & 88.55 \\
\hline Cuni NCTC 9529 & 93.36 & 89.33 & 89.04 & - & 89.16 & 93.87 & 89.33 & 93.71 \\
\hline Cmuy ATCC 51329 & 88.5 & 92 & 91.67 & 89.21 & - & 88.6 & 92.03 & 88.77 \\
\hline Cmal LMG 23826 & 94.59 & 88.76 & 88.46 & 93.77 & 88.57 & - & 88.72 & 92.13 \\
\hline Cdublau LMG 23824 & 88.6 & 98.27 & 97.29 & 89.26 & 91.96 & 88.77 & - & 88.79 \\
\hline Ctur z3032 & 91.88 & 88.82 & 88.54 & 93.64 & 88.77 & 92.1 & 88.82 & - \\
\hline
\end{tabular}

${ }^{a}$ Numbers in bold represent pairwise comparisons that are higher than the current species level threshold, 95.00 for ANI, indicating same species. 


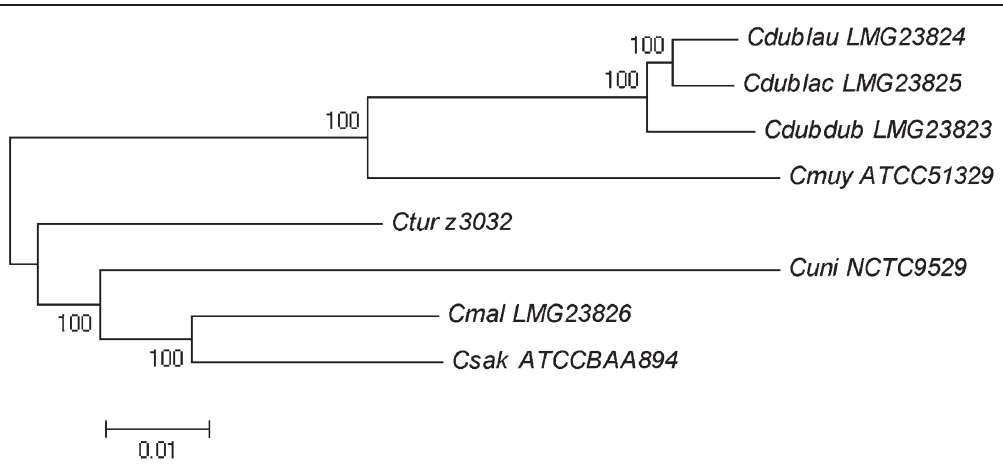

Figure 1 Evolutionary relationships of eight Cronobacter genomes. Neighbor-Joining phylogenetic tree based on 574,352 bp alignment of homologous sequences was computed using the Maximum Composite Likelihood method for nucleotide substitution. The bootstrap supports, as percentage, are shown next to the branches. The scale bar represents 0.01 base substitutions per site.

genes, opp oligopeptide transporter system, $d p p$ dipeptide transporter, sap peptide transporter, cellulose biosynthesis genes (bcs, yhj), kps capsule polysaccharide biosynthesis cluster, glucans biosynthesis cluster, dimethyl sulfoxide reductase, alkanesulfonate monoxygenase and transporter, $y t f$ putative sugar transporter operon, and hexuronate operon (Additional file 1: Table S1).

\section{Cronobacter spp. pan-genome}

For the approximately 900 non-core CDS in each of the six Cronobacter genomes; i.e., not included in the Cronobacter core genome, we determined which chromosomal genes comprised dispensable and unique genomic regions (GR) and which were putative mobile genomic islands and elements. Plasmid genes (approximately 130 CDS per genome, see Additional file 2: Table S2) were not investigated in this study. In total, we identified 84 dispensable genomic regions that were present in two or more Cronobacter genomes, and 45 unique genomic regions (Table 3 ). We overlaid these combined 129 genomic regions onto the genome-scale phylogeny, determined by alignment of orthologous sequence of the core genome (Figure 2).

In addition to the extant Cronobacter spp. core genome described earlier (Additional file 1: Table 1), a number of dispensable or accessory genomic regions, 39 in all, were identified as being a likely component of the last common ancestor core genome (Figure 2). These included metabolic operons for the utilization of taurine, inositol, malonate, and dulcitol (galactitol); two chaperone-usher fimbriae operons and curli biosynthetic genes; a CRISPR element; an alpha- and betaglucosidase; genes encoding the yih environmental persistence capsule described in Salmonella species; two large repetitive protein/hemolysin clusters; spermidine uptake system; nitric oxide reductase system; a 58.4-kb genomic region missing in Cuni NCTC9529 containing gene clusters for the reduction of dimethyl sulfoxide, uptake of biotin and urea (urt), and a multiple antibiotic resistance cluster; as well as several genomic regions containing largely hypothetical protein encoding genes (Figure 2, Table 3).

We also identified 45 non-core dispensable genomic regions, which were acquired by two or more species of Cronobacter after diverging from their most recent common ancestor. This subset of genomic regions included 12 that were present in the Cdub-Cmuy cluster and included two ferrichrome iron receptors, $f c T$ and $f c u A$ orthologues [29]; methionine and ethanolamine utilization gene clusters; and tryptophanase (indole). Additional noncore genomic regions included a $\beta$ class (GR76, Csak and Cdublac), a $\gamma 1$ class (GR82, Cmal and Csak) and a $\gamma 4$ class chaperone-usher fimbriae (GR52, Cdub and Ctur); an oligopeptide transport system (GR59, Cdub); pyridoxine metabolism cluster (GR70, Cdublac and Cdublau); maltose uptake system (GR72, Cdublac and Cmuy); cellulose degradation operon (GR73, Cdublac and Cmuy); and an $\alpha$-mannosidase (GR78, Csak and Ctur).

Each Cronobacter genome contained a number of unique genomic regions; however, the vast majority of these contained genes encoded hypothetical proteins. Notable exceptions to this trend were genomic regions encoding for mannan degradation (GR92, Cdublau); L-rhamnose ABC transporter (GR102, Cmuy); urea decomposition (GR103, Cmuy); dnd (degradation during electrophoresis), DNA sulfur modification system, (GR110 Ctur); heteropolysaccharide degradation (GR104, Ctur); putative epoxide hydrolase gene cluster (GR113, Cuni); $\kappa$ class chaperoneusher fimbriae (GR112, Cuni); invasin locus (GR123, Csak); $\gamma 1$ class chaperone-usher fimbriae (GR126, Csak); and sialic acid utilization (GR127 and 129, Csak) (Table 3).

A number of chromosomal loci were found to harbor multiple genomic islands (Table 3, shared locus); for example, GR 33 and 99 in Cmuy ATCC 51329 (Table 3). Additionally, there were two insertion sites; namely, tRNAPro-GGG and the TCA cycle isocitrate dehydrogenase 
Table 3 Non-core and unique genomic regions (GRs) identified in eight Cronobacter genomes

\begin{tabular}{|c|c|c|c|c|c|c|c|c|c|c|}
\hline GR\# & Feature(s) or putative feature $(s)^{a}$ & Cdubdub & Cdublac & Cdublau & Cmuy & Ctur & Cuni & Cmal & Csak & $\begin{array}{l}\text { Shared } \\
\text { locus }\end{array}$ \\
\hline 1 & Acyl reductase-transketolase & - & + & + & + & + & + & + & + & \\
\hline 2 & Taurine metabolism & - & + & + & + & + & + & + & + & \\
\hline 3 & Environmental persistence capsule, yih & - & + & + & + & + & + & + & + & \\
\hline 4 & Filamentous hemagglutinin outer membrane protein & + & + & + & - & + & + & + & + & \\
\hline 5 & ybh transporter, putative antibiotic resistance efflux pump & + & + & + & - & + & + & + & + & \\
\hline 6 & $\gamma_{4}$ fimbriae & + & + & + & - & + & + & + & + & \\
\hline 7 & Phospho-alpha-glucosidase (a-methyl D-glucoside) & + & + & + & - & + & + & + & + & \\
\hline 8 & DMSO, urea (urt), biotin utilization, MAR (4-aminobutyrate) & + & + & + & + & + & - & + & + & \\
\hline 9 & $\pi$ fimbriae & + & + & + & + & + & + & + & - & \\
\hline 10 & Hydrolase & + & + & + & + & + & + & + & - & \\
\hline 11 & Transporter and Rhodanese-related sulfurtransferases & + & + & + & + & + & + & + & - & । \\
\hline 12 & Lysozyme, virulence regulator & + & + & + & + & + & + & + & - & \\
\hline 13 & LPS/core OS 2 gene pair & + & + & + & + & + & + & + & - & \\
\hline 14 & MFS transporter, regulator and dehydrogenase & + & - & - & + & + & + & + & + & f \\
\hline 15 & Membrane hydrolase & + & + & - & + & - & + & + & + & \\
\hline 16 & Large repetitive hemolysin & + & + & - & + & + & + & + & - & \\
\hline 17 & Putative $\mathrm{ABC}$ transporter and $\mathrm{DMT}$ permease & + & + & + & - & + & + & + & - & $d$ \\
\hline 18 & Beta-glucosidase & + & + & + & + & - & - & + & + & \\
\hline 19 & Hypothetical proteins & + & + & + & + & - & + & + & - & \\
\hline 20 & Fatty acid desaturase & + & + & + & + & + & - & - & + & \\
\hline 21 & OM autotransporter barrel & + & + & + & + & + & + & - & - & a \\
\hline 22 & NO reductase & + & + & + & + & + & + & - & - & \\
\hline 23 & Oxidoreductase & + & + & + & + & + & + & - & - & \\
\hline 24 & Spermidine-preferential uptake system & + & + & + & + & + & + & - & - & \\
\hline 25 & Glucuronyl hydrolase, sucrose permease & + & + & + & + & + & + & - & - & \\
\hline 26 & Hypothetical proteins & + & + & + & - & + & + & - & - & \\
\hline 27 & Hypothetical proteins & + & - & + & - & + & + & + & - & \\
\hline 28 & CRISPR & + & + & - & - & + & - & + & + & \\
\hline 29 & Inositol & + & + & - & + & + & + & - & - & \\
\hline 30 & Non-heme chloroperoxidase, MxcK & - & - & - & + & + & + & + & + & g \\
\hline 31 & Acetyltransferase & - & - & - & + & + & + & + & + & \\
\hline 32 & Hypothetical proteins & - & + & + & + & - & + & + & - & \\
\hline 33 & Putative membrane protein and regulator & + & + & + & + & - & + & - & - & h \\
\hline 34 & Malonate & + & - & - & + & + & + & + & - & \\
\hline 35 & Formate dehydrogenase & + & - & - & - & + & + & + & + & \\
\hline 36 & Phenolic sulfur ester & + & + & + & + & - & - & - & - & \\
\hline 37 & Deoxyguanosinetriphosphate triphosphohydrolase & + & + & + & + & - & - & - & - & \\
\hline 38 & Ferrichrome iron receptor & + & + & + & + & - & - & - & - & \\
\hline 39 & Putative membrane and hypothetical proteins & + & + & + & + & - & - & - & - & $\mathrm{i}$ \\
\hline 40 & Arylsulfatase & + & + & + & + & - & - & - & - & j \\
\hline 41 & Redundant methionine transporter & + & + & + & + & - & - & - & - & \\
\hline 42 & Ethanolamine permease and deaminase & + & + & + & + & - & - & - & - & \\
\hline
\end{tabular}


Table 3 Non-core and unique genomic regions (GRs) identified in eight Cronobacter genomes (Continued)

\begin{tabular}{|c|c|c|c|c|c|c|c|c|c|c|}
\hline 43 & Ferrichrome-iron receptor & + & + & + & + & - & - & - & - & \\
\hline 44 & Hypothetical proteins & + & + & + & + & - & - & - & - & \\
\hline 45 & Ornithine monooxygenase, BtrH & + & + & + & + & - & - & - & - & \\
\hline 46 & Transmembrane tRNA/peptide synthetase & + & + & + & + & - & - & - & - & \\
\hline 47 & Indole & + & + & + & + & - & - & - & - & \\
\hline 48 & Putative LPS modification operon & - & - & - & - & + & + & + & + & i \\
\hline 49 & Toxin-antitoxin pair & - & - & - & - & + & + & + & + & \\
\hline 50 & Exported protein & - & - & - & - & + & + & + & + & \\
\hline 51 & CynX & + & + & + & - & - & - & + & - & \\
\hline 52 & $\gamma_{4}$ fimbriae & + & + & + & - & + & - & - & - & I \\
\hline 53 & Acyl enzymes & + & + & + & - & + & - & - & - & \\
\hline 54 & Membrane protein & - & + & + & - & + & - & - & + & \\
\hline 55 & Curli & + & - & - & - & + & + & + & - & \\
\hline 56 & Methyl-accepting chemotaxis and/or hypothetical protein & + & + & - & - & + & + & - & - & $\mathrm{n}$ \\
\hline 57 & Macrophage infectivity potentiator-related protein and regulator & - & - & - & + & + & - & + & + & \\
\hline 58 & Putative monooxygenase and transcriptional regulators & + & + & + & - & - & - & - & - & $d$ \\
\hline 59 & Oligopeptide transport system & + & + & + & - & - & - & - & - & \\
\hline 60 & Hypothetical proteins & + & + & + & - & - & - & - & - & \\
\hline 61 & Methyl-accepting chemotaxis and/or hypothetical proteins & + & + & + & - & - & - & - & - & \\
\hline 62 & Beta-lactamase & - & - & - & - & - & + & + & + & j \\
\hline 63 & Peptide chain release factor & - & - & - & - & + & + & + & - & \\
\hline 64 & Chemotaxis & - & - & - & + & - & + & + & - & e \\
\hline 65 & Helicase & - & + & + & + & - & - & - & - & \\
\hline 66 & Hypothetical proteins & - & - & + & - & - & + & - & + & \\
\hline 67 & Dulcitol & - & - & - & + & + & + & - & - & \\
\hline 68 & Short-chain dehydrogenase and regulator & + & - & + & - & - & - & - & - & $d$ \\
\hline 69 & Type I RMS & - & + & + & - & - & - & - & - & c \\
\hline 70 & Pyroxidine/pyroxidal metabolism & - & + & + & - & - & - & - & - & e \\
\hline 71 & qseBC, ompV & - & + & + & - & - & - & - & - & f \\
\hline 72 & Maltose phosphate PTS and glucosidase & - & + & - & + & - & - & - & - & \\
\hline 73 & Cellulose degradation & - & + & - & + & - & - & - & - & \\
\hline 74 & Transporter and secreted pair & - & - & - & + & - & - & - & + & \\
\hline 75 & Hypothetical proteins & - & - & - & + & - & - & - & + & \\
\hline 76 & $\beta$ fimbriae & - & + & - & - & - & - & - & + & \\
\hline 77 & Periplasmic or lipo-protein & - & - & - & - & + & - & - & + & \\
\hline 78 & a-mannosidase & - & - & - & - & + & - & - & + & \\
\hline 79 & Regulator and hypothetical protein & - & - & - & - & + & + & - & - & \\
\hline 80 & Short chain dehydrogenase & - & - & - & - & + & + & - & - & \\
\hline 81 & Membrane protein & - & - & - & - & - & - & + & + & \\
\hline 82 & $\gamma_{1}$ fimbriae & - & - & - & - & - & - & + & + & \\
\hline 83 & $(+/-)$ putative membrane and $(+/-)$ hypothetical proteins; variable & + & + & + & + & - & + & + & - & \\
\hline 84 & $\begin{array}{l}\text { Arsenic resistance; MFS transporter, regulator and hypothetical } \\
\text { proteins }\end{array}$ & + & - & - & - & - & - & - & - & i \\
\hline 85 & $\begin{array}{l}\text { Putative monoamine oxidase, carboxymuconolactone } \\
\text { decarboxylase and hypothetical proteins }\end{array}$ & + & - & - & - & - & - & - & - & I \\
\hline
\end{tabular}


Table 3 Non-core and unique genomic regions (GRs) identified in eight Cronobacter genomes (Continued)

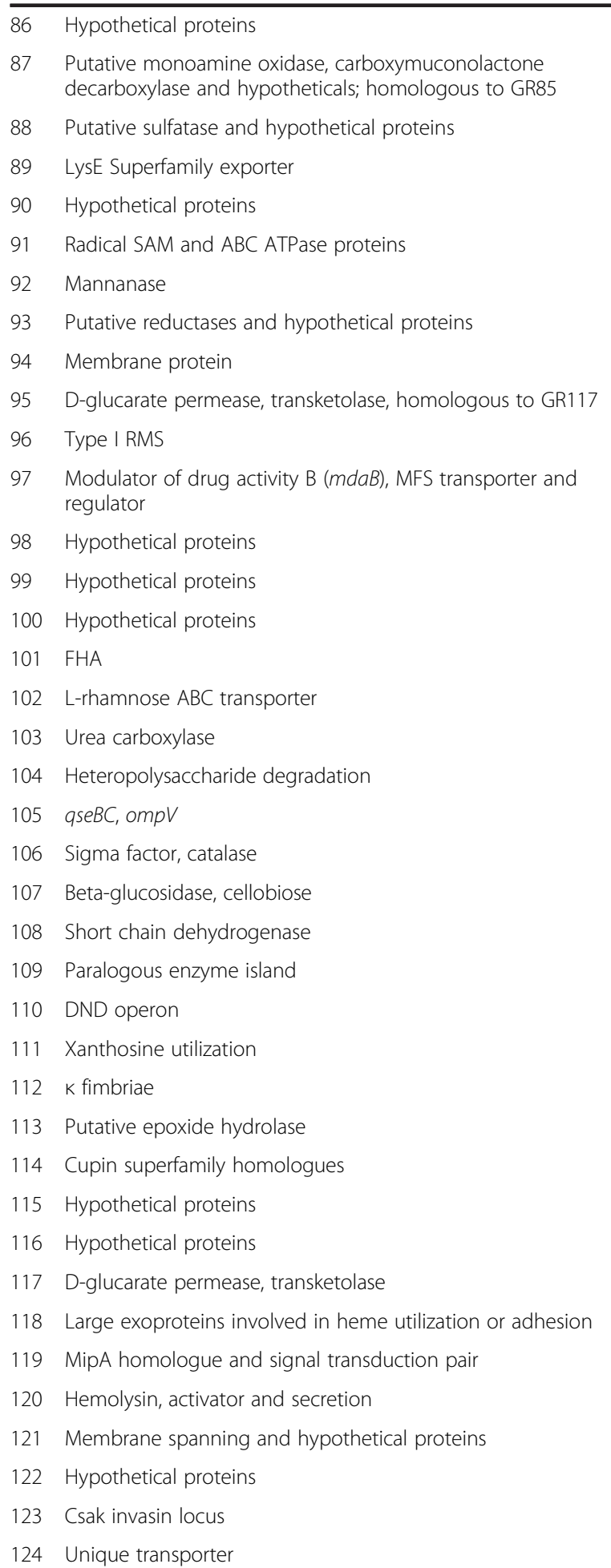


Table 3 Non-core and unique genomic regions (GRs) identified in eight Cronobacter genomes (Continued)

\begin{tabular}{|c|c|c|c|c|c|c|c|c|c|}
\hline 125 & Nucleoside-sugar efflux & - & - & - & - & - & - & - & + \\
\hline 126 & $\gamma_{1}$ fimbriae & - & - & - & - & - & - & - & + \\
\hline 127 & nanC, sugar isomerase, hydrolase & - & - & - & - & - & - & - & + \\
\hline 128 & Paralogous enzyme island & - & - & - & - & - & - & - & + \\
\hline 129 & Sialic acid & - & - & - & - & - & - & - & + \\
\hline
\end{tabular}

${ }^{\mathrm{a}} \mathrm{Feature(s),} \mathrm{or} \mathrm{putative} \mathrm{feature(s),} \mathrm{were} \mathrm{assigned} \mathrm{based} \mathrm{on} \mathrm{BLASTp} \mathrm{homology} \mathrm{of} \mathrm{encoded} \mathrm{ORFs} \mathrm{to} \mathrm{known} \mathrm{proteins.} \mathrm{Shared} \mathrm{chromosomal} \mathrm{loci} \mathrm{of} \mathrm{genomic} \mathrm{regions}$ are indicated by matching letters. Features in bold are biochemical traits, used previously to biotype Cronobacter isolates.

gene, icdA, where several small genomic regions were inserted in a multiple cassette fashion for several genomes, indicating insertion loci of genomic plasticity (Table 3, Table 4).

\section{Cronobacter spp. mobilome}

Not surprisingly, each Cronobacter genome contained multiple prophage or prophage-like elements (Table 4, Figure 3). In several cases, prophages of different Cronobacter genomes were inserted at the same chromosomal locus (Table 4, Figure 3). Indeed, phylogenetic analysis of the integrase gene of all prophages revealed a trend of several clusters in which the chromosomal insertion site was shared among all members of a phylogenetic cluster (Additional file 3: Figure S1). Interestingly, the genomes of C. universalis NCTC 9529 and C. muytjensii
ATCC 51329 harbor a $57 \mathrm{~kb}$ integrative conjugative element (ICE), which is $99 \%$ identical between strains (Table 4). This mobile genetic element is most closely related to the ICE-KKS family of integrating and conjugative elements, found in $\beta$ - and $\gamma$ - proteobacteria and represented by $\mathrm{ICE}_{\mathrm{KKS} 102} 4677$, which carries polychlorinated biphenyl degradation genes [30]. For the Cronobacter ICE, in addition to the conjugal transfer, integrase, and replication/partition genes, there is a $21 \mathrm{~kb}$ internal segment which carries unique genes among this class of ICEs. Most of the genes were annotated as encoding hypothetical proteins, so it is unclear what phenotypic trait or characteristic(s) are encoded in this region.

Additionally, each genome contained a number of transposons (Table 4). Phylogenetic analysis of the transposases clustered the genes together based on multiple copies of

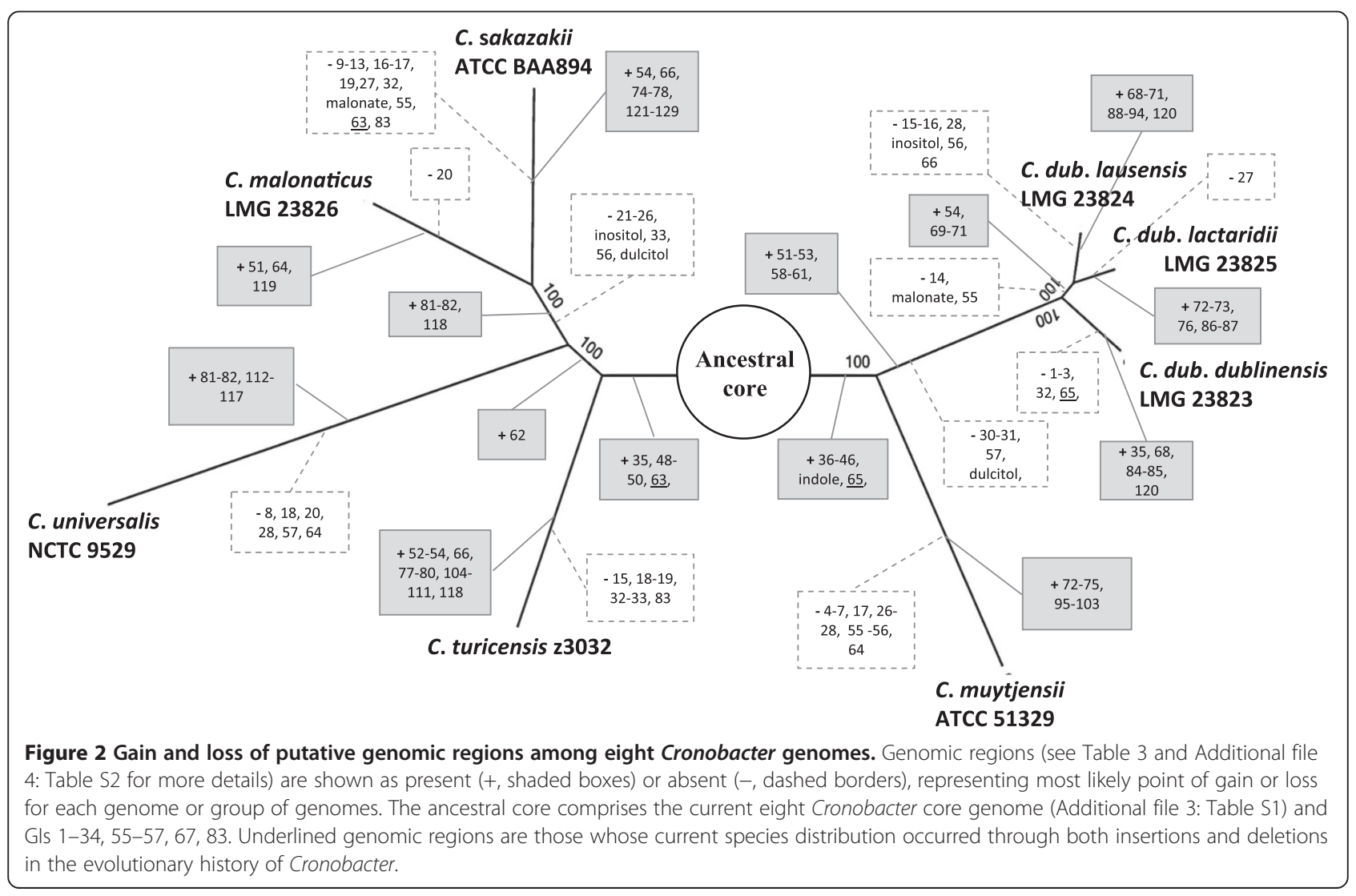


Table 4 Putative mobilome of Cronobacter genomes

\begin{tabular}{|c|c|c|}
\hline Putative mobile element & Insertion site & $\begin{array}{l}\text { Other elements at this } \\
\text { chromosomal locus }\end{array}$ \\
\hline T6SS1 (Csak) & tRNA-Phe-GAA & \\
\hline T6SS2 (Csak, Cmal, Cuni, Cdublau, Ctur) & tRNA-Phe-GAA & GR 21, 88, 121 \\
\hline Transposon-Phage (Cuni) & tRNA-Met-CAT & GR 122 (Csak) \\
\hline Prophage (Cdublac, Ctur); small integron (Cmal) & tRNA-gly-CCC & GR 112 (Cuni) \\
\hline $\begin{array}{l}\text { Prophage (Cdublac, Cmal, Ctur); tandem prophages (Cdubdub); } \\
\text { Prophage-transposon (Cdublau); transposon (Cuni) }\end{array}$ & $\begin{array}{l}\text { putative serine chemoreceptor } \\
\text { protein gene }\end{array}$ & GR 16 \\
\hline Prophage (Csak) & large repetitive protein gene & \\
\hline IS (Cmuy) & $y f g G$ & GR 104, 113 \\
\hline Prophage (Cdubdub, Cmal); transposon (Ctur) & tRNA-Arg-CCT & GR 69, 95 \\
\hline Prophage (Cdubdub, Csak) & tRNA-Pro-GGG & GR $17,58,68,89,96,105,114,123$ \\
\hline TE (Cmal) & hydroxyethylthiazole kinase gene & \\
\hline O-antigen region & galf-gnd & \\
\hline IS (Cmuy) & tRNA-Asn-GTT & GR 27 \\
\hline T6SS3 (missing in Cmuy) & tRNA-Asn-GTT & \\
\hline $\begin{array}{l}\text { Prophage (Cdublau); T6SS4 with transposon interruption (Cdublau), } \\
\text { or at end (Cdublac) }\end{array}$ & tRNA-Asn-GTT & \\
\hline Prophage (Cmal) & fliE & \\
\hline ICE (Cmuy) & $m s d B$-pykA intergenic & \\
\hline Prophage (Cdubdub) & SraC/RyeA RNA & GR81 \\
\hline Prophage (Cmal); TE (Ctur) & $y \operatorname{cgN}$ & \\
\hline Transposon (Cdublau) & interruption GR 59 & \\
\hline Prophage (Cdublau, Cmuy, Csak) & ycjR-ycjS & \\
\hline Tellurium resistance transposon (Csak) & interruption GR 8 & \\
\hline Transposon (Cuni) & GR 30 & GR 92 \\
\hline Transposon (Cdubdub) & uvdE & \\
\hline IS600 (Cdub); Prophage (Cdublau) & $y d c W$ intergenic & GR 31 (variable) \\
\hline Prophage (Cuni) & phnO intergenic & \\
\hline T6SS5 (highly variable, missing in Cdublac, Cmuy) & tRNA-Val-GAC & GR 33, 99 \\
\hline $\begin{array}{l}\text { Copper-resistance transposon (Cuni (+ABC transporter), Cmuy); } \\
\text { Prophage (Cmuy, Ctur) }\end{array}$ & $i c d A$ & GR 39, 48, 84, 87, 93, 116, 119 \\
\hline Prophage (Csak) & $y c d x$ & \\
\hline Prophage (Cdublau) & mntR-ybiP intergenic & \\
\hline Prophages (Cuni, Csak, Ctur); T6SS6 (Cdub, Ctur, Csak - truncated) & tRNA-Arg-TCT & GR $11,52,85$ \\
\hline Prophage (Csak); Transposon (Cmal), TE (Cdublau) & tRNA-Thr-CGT & \\
\hline TE (Cmal) & pilB & \\
\hline $\begin{array}{l}\text { Prophage (Cdublac, Cmal); TE (Cdublau, Cdubdub, Cuni); Transposon } \\
\text { (Cdublau) }\end{array}$ & tRNA-Leu-CAA & GR 110 \\
\hline ICE (Cuni) & large repetitive protein gene & \\
\hline T6SS7-repeat region (all, variable and conserved genes) & tpiA intergenic & \\
\hline Small integron (Csak) & yicC-yicG & \\
\hline Core OS variable region & $k d t B-k b l$ & \\
\hline Prophage (Cmuy); TE (Cdubdub, Cuni) & tRNA-SeC(p)-TCA & \\
\hline Copper and silver-resistance transposon (Csak) & yhiN-puuA & \\
\hline
\end{tabular}




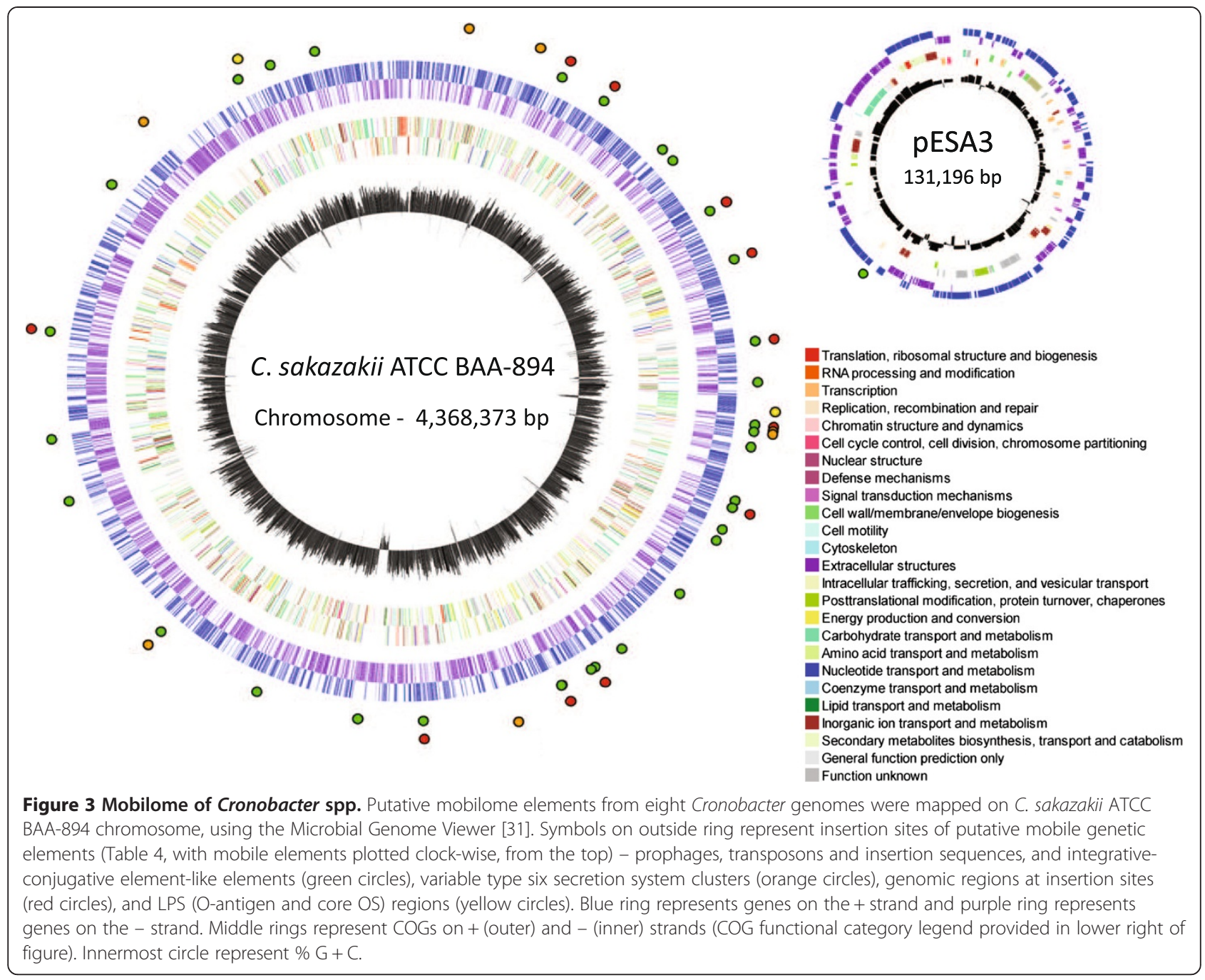

the same transposon found in each genome, but not with regard to insertion site (Additional file 4: Figure S2). Most of the transposons carried very few additional genes or hypothetical protein encoding genes. There were three noticeable exceptions, a transposon carrying the tellurium resistance island found in the genome of Csak BAA-894, a transposon carrying a copper resistance island found in the genomes of Cuni NCTC 9529 and Cmuy ATCC 51329, inserted near the isocitrate dehydrogenase gene, $i c d A$, and a transposon inserted in the $y$ hiN - puuA intergenic region of Csak BAA-894, carrying copper and silver resistance genes (Table 4, Additional file 2: Table S2).

We also observed a number of type six secretion system (T6SS) gene clusters in the eight Cronobacter genomes (Table 4, Figure 3, Additional file 2: Table S2). All genomes contained a very large T6SS cluster as a component of the Cronobacter core genome, which is flanked by a highly variable region of different sizes in each genome containing several hypothetical protein CDS as well as those encoding numerous homologues of $v g r G$, Rhs-family and YD-repeat proteins (Table 4, T6SS7; Additional file 2: Table S2). Additionally, seven of the eight genomes contain four to six accessory T6SS clusters; Cmuy ATCC 51329 does not contain any additional T6SS clusters. The gene content of each cluster is variable between clusters present at different chromosomal loci, but largely conserved among clusters located at the same chromosomal locus. Previously, we reported the presence of a T6SS cluster on a repFIB plasmid in strains of C. sakazakii [23].

Not surprisingly, many of the mobile genetic elements, such as lysogenic prophages, in Cronobacter genomes are inserted at tRNA loci (Table 4). We also found T6SS gene clusters and some genomic regions inserted at tRNA sites. And as with genomic regions, we observed cassette-like insertion of multiple types of genetic elements at single sites (Table 4).

\section{Discussion}

Like many bacterial genera, the taxonomy of Cronobacter has evolved and expanded as more sensitive molecular- and 
sequence-based tools have developed. In this study, we performed two genome-scale sequence analyses to discern the taxonomic relationships of extant Cronobacter species, namely ANI and genome-scale alignment and phylogenetic reconstruction using syntenic, orthologous chromosomal sequence. The taxonomic reclassification by Iversen et al. [1], which relied on both DNA studies and on results from biochemical tests, was confirmed by both analyses. We found that the ANI results from this study were more meaningful in discerning relationships between pairs of Cronobacter species that are more distantly related as compared to DNA-DNA hybridization [1]. This is most likely a reflection of the differences in the range of meaningful values for each analysis.

We were able to confirm the presence or absence of eight of the genetic determinants of the biochemical characteristics used previously for Cronobacter biotyping (Table 3); namely, indole (tryptophanase), dulcitol (galactitol), malonate, myo-inositol, and two genomic regions that are likely responsible for utilization of 4aminobutyrate and production of $\alpha$-methyl glucoside (Farmer biotype 15 [2]), as well as those biotyping traits contained in the core genome of these eight strains, utilization of palatinose and putrescine (Additional file 1: Table S1). The distribution of these operons and genes were in complete agreement with the biochemical results and species description reported by Iversen et al. [1]. Inositol fermentation has recently been proposed as a marker of pathogenicity for Cronobacter, based on the presence of the inositol monophosphatase gene $(\operatorname{suh} B)$ in pathogenic strains [32]. In this study, we found that this gene, which is seemingly ubiquitous and highly conserved among the Enterobacteriaceae, is a component of the Cronobacter core genome (Additional file 1: Table S1). Additionally, we found that the inositol utilization operon (GR29, Table 3, Additional file 2: Table S2) was present, and functional [1], in the genomes of strains isolated from the environment (water sources), Cuni NCTC 9529 ${ }^{\mathrm{T}}$, Cdubdub LMG $23823^{\mathrm{T}}$, Cdublac LMG $23825^{\mathrm{T}}$, and absent in the genomes of pathogenic strains, Cmal LMG $23826^{\mathrm{T}}$ and Csak BAA-894.

Using comparative genomics, we were able to define the syntenic Cronobacter core genome for the eight species genomes analyzed in this study, which is approximately $77 \%$ of the total protein coding sequences, on average, per genome. This value is considerably higher as compared to the core genome content of other genera. In fact, the core genus genome size of Cronobacter is comparable to the core genome size of certain bacterial species [33,34], and considerably larger than that of the related E. coli [35]. This is a reflection of the phylogenetic closeness of this genus, as shown in the ANI results (Table 2), and indicative of a more "closed" Cronobacter genome.
The core genome size is considerably higher than that reported by Kucerova et al. [20], 1,899 genes, which incorporated four of the six strains used in this study. This discrepancy is best explained by the divergent evolution of the genus to form two distinct clades (Figure 1). This divergent evolution would undoubtedly have a significant impact on the efficiency of hybridization of probes designed from the sequence of Csak BAA-894 to DNA from strains of Cdub and Cmuy, resulting in the smaller reported core genome size [20]. With regard to the genomic regions revealed by the comparative genomic hybridization analysis of Csak BAA-894, reported by Kucerova et al. [20], we classified 12 of the 15 reported genomic regions as part of the Cronobacter mobilome. They included T6SS clusters, GR1, 2 (ESA_0292-00302), 9, and 15 (repFIB plasmid-associated T6SS); putative prophages, GR3, 4, 6, 10, 11, 12; transposons, GR7, 14; and O-antigen gene clusters, GR5 (Additional file 2: Table S2, from [20]).

The comparably large core genome size and overall high sequence identity within the genus support the hypothesis that these two clades have evolved as a result of sympatric speciation; however, the divergence of the two clades indicates that they are under different evolutionary pressures, to some degree. In addition to the divergent evolution of shared genome content, several noncore genomic regions were found to be either present (or absent) in one of the two species-complex clades. For example, the Cdub-Cmuy clade has acquired 13 genomic regions that are not present in the Csak-Cmal-CuniCtur clade (Figure 2).

An examination of the dispensable gene content of each species provides clues as to differences in environmental niches and pathogenicity, such as virulence potential. Among putative virulence-related properties, the presence and diversity of appendages within the Cronobacter genus is intriguing. Many causative agents of meningitis, such as Neisseria meningitidis, Haemophilus influenzae, and Pseudomonas aeruginosa encode for type IV pili (TFP), necessary to colonize in the face of shear forces of blood flow, associated with the capillary beds of the blood-brain barrier. The Cronobacter core genome also contains the genes that encode a TFP. Bioinformatically, the presence of a TFP, as opposed to a T2SS, was hypothesized due to the presence of the TFPunique gene, pilT, and the genetic organization of the pilQ loci, similar to the TFP of $P$. aeruginosa. Several chaperone-usher fimbriae were also present in the core genome. Additionally, seven other chaperone-usher fimbriae were differentially distributed among the eight genomes analyzed in this study (Table 3 ), including a $\mathrm{P}$ pilus homologue (GR9, missing in Csak BAA-894), which is a prominent virulence factor of uropathogenic E. coli, also a causative agent of neonatal meningitis. 
Csak BAA-894 and Cmal LMG $23826^{\mathrm{T}}$ harbor a unique type I fimbriae (GR82), which is absent in the other genomes, and Csak BAA-894 also harbors a $\beta$ class CU fimbriae (GR76), shared with Cdublac LMG $23825^{\mathrm{T}}$, and a second, unique type I fimbriae (GR126, which corresponds to GR8 of Kucerova et al. [20]). Of interest is the finding that Cmuy ATCC $51329^{\mathrm{T}}$ possesses only one additional fimbriae operon, in addition to those encoded in the genus core genome. Some genomes also harbored curli biosynthesis genes, homologous to curli of $E$. coli and tafi fimbriae of Salmonella. Although implicated directly in cell-cell contact and biofilm formation, these organelles likely contribute to the colonization of Cronobacter, after initial cell attachment has taken place. We hypothesize that this operon was a component of the ancestral core, and has been lost in all strains of $C$. sakazakii and C. muytjensii (data not shown).

In addition to appendages potentially involved in adhesion, several type $\mathrm{V}(\mathrm{a})$, or autotransporter, secretion loci are present in the genomes of the Cronobacter analyzed in this study, which are annotated as hemolysin, adhesin, outer membrane autotransporter barrel, filamentous hemagglutinin, large exoproteins, etc. They are found as accessory genomic regions (GRs 4, 16, 21, 50, 101, 123), and present as single genes or pairs of genes in the core genome (Additional file 2: Table S2). Of particular interest is GR123, found exclusively in Csak BAA-894, and GR118, found in the three routinely isolated pathogenic species, Ctur, Cmal, and Csak. GR123 contains two putative invasins and an eae homologue and may constitute a pathogenicity island. This region was found to be present in the genomes of three neonatal intensive care unit (NICU) outbreak strains (including Csak BAA-894) and absent in the C. sakazakii type strain, ATCC 29544, which was isolated from a child's throat (defined as a component of cluster 3, Additional file 1: Table S1, from [20]).

Also interesting is the presence of two genomic regions (GRs 127 and 129) involved in the utilization of sialic acid in the genome of Csak BAA-894. Sialic acid is a generic term for a family of derivatives of the nine carbon sugar acid, neuraminic acid, which are found at surface-exposed end positions of eukaryotic, primarily animal, tissues. Many pathogens have evolved to either coat their surfaces with sialic acid derivatives, in order to evade the innate immune response, or to use this biopolymer as a nutrient source [36]. In addition to Csak BAA-894, we found that 55 out of 57 strains of $C$. sakazakii are able to utilize N-acetyl-neuraminic acid, a derivative of sialic acid (by Biolog PM Microarray, data not shown). Conversely, no other Cronobacter strains were able to utilize this substrate, except four of six $C$. turicensis strains (data not shown).

It has been hypothesized that the environmental niche of Cronobacter is as a plant commensal [37]. Accordingly, we found several genomic features, both in the Cronobacter core- and pan-genome, which would be beneficial for an organism to possess in this habitat. For example, the Cronobacter core genome contains the maltose transporter operon, malGFE- malKlamBmalM, repressor, malT, and $\alpha-$ glucosidases that can hydrolzye maltose to two glucose molecules. Maltose is primarily restricted to plants, particularly seed tissues. An operon for the transport and hydrolysis of isomaltulose is also present in the core genome of Cronobacter, in agreement with the taxonomic description of Iversen et al. [1], and previously reported by Lehner et al. [38]. Isomaltulose (palatinose), also used in the original Cronobacter biotyping scheme, is a disaccharide of glucose and fructose and a component of honey and sugar cane. Additionally, we found the following characteristics in the core Cronobacter core genome: utilization of arabinogalactan, a major component of plant gums; transport and utilization of xylose, a precursor to hemicellulose; galacturonate, the principal component of pectin; albicidin, a phytotoxin of Xanthomonas spp., resistance; $\beta$-carotene pigmentation, and several $\alpha$ and $\beta$ glucosidases.

It is of interest to find that an albicidin resistance protein coding gene was found as a core genome component. Albicidin is a bacteriocin-like molecule that degrades DNA gyrase, both of bacterial and chloroplast origins [39]. Speculatively, Cronobacter possessing a gene promoting resistance to the action of albicidin adds further evidence for a plant-associated evolutionary history, as well as, the impartation of a competitive edge to Cronobacter survival in a mixed organism environment where competition is controlled through the action of bacteriocin expression. In addition to these conserved features, several other genomic regions and operons were found that have putative functions for plant association, or homologies to proteins from plant commensals. These include GR95/117 of Cmuy ATCC 51329 and Cuni NCTC 9529; GR70, metabolism of pyroxidine/ pyroxidal (vitamin $\mathrm{B}_{6}$ ), of which green plants and grains and nuts contain high amounts; GR72, maltose derivative metabolism; GR73, galactose (glycoside-pentosidehexuronide) homologue permease (possible role in cellulose degradation); GR92, mannanase; GR102, Lrhamnose ABC transporter; and GR107 of Ctur z3032.

Several inherent properties of Cronobacter have been proposed as mechanisms that aid the bacteria in survival and persistence in dried foods, such as PIF, food powders, and spices. Chief among these have been enhanced heat resistance, as compared to other enterics and contaminating microorganisms. However, most studies have reported variable results in terms of heat resistance at the strain level, and cross-tolerance to other environmental stressors, such as $\mathrm{pH}$ and water activity. One consistent finding is an unusually high resistance to dry 
stress [17]. Accordingly, we found several genomic determinants, which would be beneficial in a dry or low water activity environment, including cellulose biosynthesis (bcs and $y h j$ ) operons, colanic acid EPS, capsular biosynthesis operon ( $k p s)$, an environmental persistence capsule (yih, GR3), and curli (GR55). Recently, it has been reported that the synergistic expression of the yih operon encoded capsule, cellulose and curli or tafi provides resistance to desiccation stress in Salmonella $[40,41]$. We hypothesize that the same genetic determinants, combined with other capsular and EPS operons, likely play a similar role in the environmental persistence and desiccation resistance in Cronobacter. Although not all Cronobacter produce curli, those species possess several other fimbriae which could substitute in this adhesin and/or scaffolding role. In addition to this extracellular matrix, we also found two operons, present in all Cronobacter genomes, that encode transporters involved in osmoprotection, yeh and bet operons, with homology to plant commensals and pathogens, such as Burkholderia and Erwinia species.

\section{Conclusions}

In conclusion, we found a large core genome among representative type species strains of the genus Cronobacter, which encodes factors for enhanced environmental persistence and plant commensalism, as well as numerous appendages that may aid in attachment and colonization, advantageous both in the environment and in the host. Conversely, we found that the genus has diverged in a bidirectional manner. The Cdub-Cmuy clade has evolved to be more adapted for primarily an environmental and plant association niche, while the other clade, particularly Csak and $\mathrm{Cmal}$, has evolved and acquired accessory genes that have enhanced its virulence capacity, and host species adaption, and promoted pathogenicity. Clearly, in silico analysis of strain level differences, coupled with experimental studies, will reveal which of these factors are most important for environmental, plant, and human pathogenic lifestyles of this group of organisms. This study establishes a powerful platform for further functional genomics research of this diverse group; an important prerequisite towards future development of countermeasures against this foodborne pathogen.

\section{Methods}

\section{Bacterial strains}

Cronobacter dublinensis subsp. dublinensis LMG 23823, C. dublinensis subsp. lausannensis LMG 23824, C. dublinensis subsp. lactaridi LMG 23825, C. malonaticus LMG 23826, and C. universalis NCTC 9529 were acquired from Dr. Carol Iversen; C. muytjensii ATCC 51329 was acquired from the American Type Culture Collection (ATCC; Manassas, VA).

\section{DNA sequencing and assembly}

Genomic DNA was fragmented to an average size of $3 \mathrm{~kb}$ using a Covaris (Woburn, MA) E210 focusedultrasonicator. Then, Multiplex Identifier (MID)-tagged, paired-end libraries were prepared using a modified version of the 454 Life Sciences (Roche, Branford, CT) protocol. The procedure has been adapted to 96-well plate format using automated pipetting robots, and includes QC steps and AMPure (Beckman-Coulter (Agencourt), Indianapolis, IN) bead-based DNA purifications between enzymatic reactions as described by Fisher et al. [42]. Libraries were pooled and sequenced using the Roche 454 FLX pyrosequencer to an average depth of $15 \times$ coverage. Raw sequence data were processed using manufacturer's software and quality filtering algorithms. Resulting demultiplexed data sets were assembled using Celera Assembler v6.1 (http://sourceforge.net/projects/ wgs-assembler/).

\section{Annotation and comparative genomics}

Genomic contigs were submitted as multiple-sequence FASTA files and annotated using the RAST annotation server [43], to identify RNAs and protein-coding genes. The RAST server is a free web portal (rast.nmpdr.org), provided by the SEED [44], which automatically and rapidly curates both closed and draft genomes using a subsystems approach, as opposed to a tedious gene by gene method. Comparative genomics was performed as previously reported [29,44-47], with some exceptions. In this study, genome to genome comparisons were performed primarily with the SEED viewer [48], which utilizes bidirectional protein-protein BLAST (blastp) sequence comparison of translated ORFs. Because sequencing resulted in draft genomes (Table 1), we used the closed genomes of C. sakazakii ATCC BAA-894 (BioProject Accession PRJNA12720) and C. turicensis z3032 (BioProject Accession PRJEA39965) as references to align draft contigs using MUMmer [49]. The syntenic core genome of Cronobacter was determined using the SEED viewer sequence based comparative genomics tool. To ensure the most complete and robust syntenic core gene set among the genomes analyzed, the genomes of C. sakazakii ATCC BAA-894 and C. turicensis z3032 were uploaded and annotated via the RAST server, and used as reference genomes for comparative genomics. For the draft genomes, genes at the end of a contig or interrupted by contig gaps were reconciled using bidirectional BLASTN analysis, against all other genomes.

Genomic regions (GR), defined as regions which are present in one or more Cronobacter genomes and missing in at least one other genome (dispensable), were identified as previously reported $[44,45,47]$. Most probable insertion and deletions of genomic regions were estimated as done previously [44], using a maximum 
parsimony approach. Clade-specific, as well as ancestral genome genomic regions were identified by collapsing shared genome genomic regions to the farthest branch point that maintained the most parsimonious outcome. For clarity, only the last common ancestor to all eight Cronobacter spp. genomes analyzed in this study is shown in Figure 2. It is assumed that each branch point would produce a hypothetical ancestral genome common to those genomes beyond that branch point. Genomic region identification numbers were assigned such that genomic regions that are unique or shared by an individual Cronobacter genome were successively numbered. Mobile genetic elements were identified in a similar fashion as genomic regions. In addition, mobility was determined based on significant identity alignments, using BLASTP, of its member ORFs to phage integrases and structural genes, transposases, and conjugative pili transfer genes, contained in the GenBank NR database.

Average nucleotide identity, by BLAST, (ANI) [50] was computed using the JSpecies package [51]. A genomescale phylogeny was computed as previously described $[44,47,52]$, with some exceptions. As opposed to using sets of orthologues of individual genes, 16 conserved chromosomal syntenic regions, were first aligned individually using MEGA version 5 [53], and then concatenated. These regions spanned the following gene loci from C. sakazakii ATCC BAA-894 (GenBank CP000783.1), ESA_00107-00117, 00146-00223, 0039900443, 00671-00737, 01048-01094, 03220-03278, 03280-03289, 03331-03353, 03358-03402, 0344703511， 03536-03550, 03554-03599, 03614-03648, 03871-03886, 03982-04015, 04016-04029, and included 591 coding sequences (CDS) and intergenic regions. Phylogenetic reconstruction was performed in MEGA, using the neighbor-joining method. The bootstrap consensus tree shown in Figure 1 was inferred from 1000 replicates. The percentage of replicate trees in which the associated taxa clustered together in the bootstrap test (1000 replicates) are shown next to the branches. The tree is drawn to scale, with branch lengths in the same units as those of the evolutionary distances used to infer the phylogenetic tree, i.e., the number of base substitutions per site, as determined using the Maximum Composite Likelihood method. The original dataset included 600,341 bps. All positions containing gaps and missing data were eliminated. There were a total of 574,352 positions in the final dataset.

\section{Accession numbers}

The Whole Genome Shotgun projects described in this study have been deposited at DDBJ/EMBL/GenBank under the accessions, C. dublinensis subsp. dublinensis LMG 23823, [GenBank: AJKZ00000000]; C. dublinensis subsp. lausanensis LMG 23824, [GenBank: AJKY000000000]; C. dublinensis subsp. lactaridii LMG 23825, [GenBank: AJKX00000000]; C. malonaticus LMG 23826, [GenBank: AJKV00000000]; C. muytjensii ATCC 51329, [GenBank: AJKU00000000]; and C. universalis NCTC 9529, [GenBank: AJKW00000000]. The versions described in this paper are the first, XXXX01000000.

\section{Additional files}

\begin{abstract}
Additional file 1: Table S1. Core genome of eight Cronobacter spp. Core genome components are shown, using Csak ATCC BAA-894 as a reference genome, to include contig, start, stop, length in bp, and \% identity (BLASTn). Genomes were annotated using the RAST server; gene identification numbers (ID) were assigned by RAST.

Additional file 2: Table S2. Feature tables of eight Cronobacter genomes. Annotated feature tables, generated by RAST, of the eight Cronobacter genomes used in this study. Each feature (column E) was assigned as a component of: a genomic region ( $G R$, column $A$ ), the mobilome (column B), a plasmid (column C), or the core Cronobacter genome (column D); however, not all features could be assigned to one of these classifications. Several feature characteristics are presented. The feature table for each genome is given as a separate worksheet, named according to the particular strain.
\end{abstract}

Additional file 3: Figure S1. Phylogenetic relationship of integrases of eight genomes of Cronobacter spp. See Additional file 2: Table S2 for further details of each putative integrase. Notation to the right of each integrase indicates insertion locus.

Additional file 4: Figure S2. Phylogenetic relationship of transposases of eight genomes of Cronobacter spp. See Additional file 2: Table S2 for further details of each putative transposase. Notation to the right of each transposase indicates insertion locus.

\section{Competing interest}

All of the authors declare that they have no competing interests.

\section{Authors' contributions}

CJG carried out the comparative genomics analyses and wrote the paper. MLK coordinated DNA sequencing with IGS (Baltimore, MD). All authors helped to draft the manuscript. FP, Cl, AL, RS, MLK, GG, SF, KAP, CJG, AAF, $K G J, V S$, and BDT conceived of the study and of the concepts involved in the formation of an international Cronobacter consortium. All authors participated in the study's design and in the coordination of efforts by the consortium. All authors read and approved the final manuscript.

\section{Acknowledgements}

We thank Lisa Sadzewicz and Luke Tallon and other support members of the Institute for Genome Sciences at the University of Maryland for their contributions to this work. We thank Christopher Elkins, Barbara McCardell, and Kevin Gaido for their help in reviewing this manuscript. The funds supporting this work were obtained internally through U.S. FDA appropriations.

\section{Author details}

${ }^{1}$ CFSAN, FDA, Laurel, USA. ${ }^{2}$ Oak Ridge Institute for Science and Education, Oak Ridge, USA. ' UCD Centre for Food Safety, School of Public Health, Physiotherapy \& Population Science, University College, Dublin \& WHO Collaborating Centre for Cronobacter, Belfield, Dublin, Ireland. ${ }^{4}$ Food Directorate / Direction des aliments, Bureau of Microbial Hazards / Bureau des dangers microbiens, Health Canada / Santé Canada, and Sir F.G. Banting Research Centre / Centre de recherches Sir F.G. Banting, Ottawa, ON, Canada. ${ }^{5}$ Nestle Research Center, Lausanne, Switzerland. ${ }^{6}$ Institute for Food Safety and Hygiene, University of Zurich, Zurich, Switzerland.

Received: 14 September 2012 Accepted: 24 May 2013

Published: 31 May 2013 


\section{References}

1. Iversen C, Mullane N, McCardell B, Tall BD, Lehner A, Fanning S, Stephan R, Joosten $\mathrm{H}$ : Cronobacter gen. nov., a new genus to accommodate the biogroups of Enterobacter sakazakii, and proposal of Cronobacter sakazakii gen. nov., comb. nov., Cronobacter malonaticus sp. nov., Cronobacter turicensis sp. nov., Cronobacter muytjensii sp. nov., Cronobacter dublinensis sp. nov., Cronobacter genomospecies 1, and of three subspecies, Cronobacter dublinensis subsp. dublinensis subsp. nov., Cronobacter dublinensis subsp. lausannensis subsp. nov. and Cronobacter dublinensis subsp. lactaridi subsp. nov. Int I Syst Evol Microbiol 2008, 58(Pt 6):1442-1447.

2. Farmer JJ, Asbury MA, Hickman FW, Brenner DJ, The Enterobacteriaceae Study G: Enterobacter sakazakii: a New species of enterobacteriaceae isolated from clinical specimens. Int J Syst Bacteriol 1980, 30(3):569-584

3. Urmenyi AMC, White Franklin A: Neonatal death from pigmented coliform infection. Lancet 1961, 277(7172):313-315

4. Iversen C, Waddington M, Farmer JJ 3rd, Forsythe SJ: The biochemical differentiation of Enterobacter sakazakii genotypes. BMC Microbiol 2006, 6:94.

5. Joseph S, Cetinkaya E, Drahovska H, Levican A, Figueras MJ, Forsythe SJ: Cronobacter condimenti sp. nov., isolated from spiced meat and Cronobacter universalis sp. nov., a novel species designation for Cronobacter sp. genomospecies 1, recovered from a leg infection, water, and food ingredients. Int J Syst Evol Microbiol 2012, 62(Pt 6):1277-1283.

6. Gosney MA, Martin MV, Wright AE, Gallagher M: Enterobacter sakazakii in the mouths of stroke patients and its association with aspiration pneumonia. Eur J Intern Med 2006, 17(3):185-188.

7. Skovgaard N: New trends in emerging pathogens. Int I Food Microbiol 2007, 120(3):217-224.

8. Drudy D, O'Rourke M, Murphy M, Mullane NR, O'Mahony R, Kelly L, Fischer M, Sanjaq S, Shannon P, Wall P, et al: Characterization of a collection of Enterobacter sakazakii isolates from environmental and food sources. Int J Food Microbiol 2006, 110(2):127-134

9. Nazarowec-White M, Farber JM: Thermal resistance of Enterobacte sakazakii in reconstituted dried-infant formula. Lett Appl Microbiol 1997, 24(1):9-13.

10. Baumgartner A, Grand M, Liniger M, Iversen c: Detection and frequency of Cronobacter spp. (Enterobacter sakazakii) in different categories of ready-to-eat foods other than infant formula. Int J Food Microbiol 2009, 136(2):189-192.

11. Jaradat ZW, Ababneh QO, Saadoun IM, Samara NA, Rashdan AM: Isolation of Cronobacter spp. (formerly Enterobacter sakazakii) from infant food, herbs and environmental samples and the subsequent identification and confirmation of the isolates using biochemical, chromogenic assays, PCR and 16S rRNA sequencing. BMC Microbiol 2009, 9:225.

12. Restaino L: "Development of an improved protocol for the isolation and detection of Enterobacter sakazakii (Cronobacter) from powdered infant formula," a comment on. J Food Prot 2010, 73(6):1016-1022. J Food Prot 2010, 73(11):1964-1966; author reply 1965-1966.

13. Noriega FR, Kotloff KL, Martin MA, Schwalbe RS: Nosocomial bacteremia caused by Enterobacter sakazakiki and Leuconostoc mesenteroides resulting from extrinsic contamination of infant formula. Pediatr Infect Dis J 1990, 9(6):447-449.

14. Breeuwer P, Lardeau A, Peterz M, Joosten HM: Desiccation and heat tolerance of Enterobacter sakazakii. J Appl Microbiol 2003, 95(5):967-973.

15. Osaili TM, Shaker RR, Olaimat AN, Al-Nabulsi AA, Al-Holy MA, Forsythe SJ: Detergent and sanitizer stresses decrease the thermal resistance of Enterobacter sakazakii in infant milk formula. J Food Sci 2008, 73(3):M154-M157.

16. Grimm M, Stephan R, Iversen C, Manzardo GG, Rattei T, Riedel K, Ruepp A, Frishman D, Lehner A: Cellulose as an extracellular matrix component present in Enterobacter sakazakii biofilms. J Food Prot 2008, 71(1):13-18.

17. Dancer Gl, Mah JH, Rhee MS, Hwang IG, Kang DH: Resistance of Enterobacter sakazakii (Cronobacter spp.) to environmental stresses. J Appl Microbiol 2009, 107(5):1606-1614.

18. Williams TL, Monday SR, Edelson-Mammel S, Buchanan R, Musser SM: A topdown proteomics approach for differentiating thermal resistant strains of Enterobacter sakazakii. Proteomics 2005, 5(16):4161-4169.

19. Gajdosova J, Benedikovicova K, Kamodyova N, Tothova L, Kaclikova E, Stuchlik S, Turna J, Drahovska H: Analysis of the DNA region mediating increased thermotolerance at 58 degrees $C$ in Cronobacter sp. and other enterobacterial strains. Antonie Van Leeuwenhoek 2011, 100(2):279-289.
20. Kucerova E, Clifton SW, Xia XQ, Long F, Porwollik S, Fulton L, Fronick C, Minx P, Kyung K, Warren W, et al: Genome sequence of Cronobacter sakazakii BAA-894 and comparative genomic hybridization analysis with other Cronobacter species. PLoS One 2010, 5(3):e9556.

21. Mange JP, Stephan R, Borel N, Wild P, Kim KS, Pospischil A, Lehner A Adhesive properties of Enterobacter sakazakii to human epithelial and brain microvascular endothelial cells. BMC Microbiol 2006, 6:58

22. Stephan R, Lehner A, Tischler P, Rattei T: Complete genome sequence of Cronobacter turicensis LMG 23827, a food-borne pathogen causing deaths in neonates. J Bacteriol 2011, 193(1):309-310.

23. Franco AA, Hu L, Grim CJ, Gopinath G, Sathyamoorthy V, Jarvis KG, Lee C, Sadowski J, Kim J, Kothary MH, et al: Characterization of putative virulence genes on the related RepFIB plasmids harbored by Cronobacter spp. Appl Environ Microbiol 2011, 77(10):3255-3267.

24. Joseph S, Sonbol H, Hariri S, Desai P, McClelland M, Forsythe SJ: Diversity of the Cronobacter genus as revealed by multilocus sequence typing. J Clin Microbiol 2012, 50(9):3031-3039.

25. Strydom A, Cameron M, Corli Witthuhn R: PCR-RFLP analysis of the rpoB gene to distinguish the five species of Cronobacter. Food Microbiol 2011, 28(8):1472-1477.

26. Li Y, Cao L, Zhao J, Cheng Q, Lu F, Bie X, Lu Z: Use of rpoB gene sequence analysis for phylogenetic identification of Cronobacter species. J Microbiol Methods 2012, 88(2):316-318.

27. Stoop B, Lehner A, Iversen C, Fanning S, Stephan R: Development and evaluation of rpoB based PCR systems to differentiate the six proposed species within the genus Cronobacter. Int J Food Microbiol 2009, 136(2):165-168.

28. Strydom A, Cameron M, Witthuhn RC: Phylogenetic analysis of Cronobacter isolates based on the rpoA and $16 \mathrm{~S}$ rRNA genes. Curr Microbiol 2012, 64(3):251-258.

29. Grim CJ, Kothary MH, Gopinath G, Jarvis KG, Beaubrun JJ, McClelland M, Tall $B D$, Franco AA: Identification and characterization of cronobacter iron acquisition systems. Appl Environ Microbiol 2012, 78(17):6035-6050.

30. Ohtsubo Y, Ishibashi Y, Naganawa H, Hirokawa S, Atobe S, Nagata Y, Tsuda M: Conjugal transfer of polychlorinated biphenyl/biphenyl degradation genes in acidovorax sp. Strain KKS102, which Are located on an integrative and conjugative element. J Bacteriol 2012, 194(16):4237-4248.

31. Kerkhoven R, van Enckevort FH, Boekhorst J, Molenaar D, Siezen RJ: Visualization for genomics: the microbial genome viewer. Bioinformatics 2004, 20(11):1812-1814.

32. Hamby SE, Joseph S, Forsythe SJ, Chuzhanova N: In Silico identification of pathogenic strains of Cronobacter from biochemical reveals association of inositol fermentation with pathogenicity. BMC Microbiol 2011, 11:204.

33. Brunner J, Wittink FR, Jonker MJ, de Jong M, Breit TM, Laine ML, de Soet JJ, Crielaard W: The core genome of the anaerobic oral pathogenic bacterium Porphyromonas gingivalis. BMC Microbiol 2010, 10:252.

34. Donati C, Hiller NL, Tettelin H, Muzzi A, Croucher NJ, Angiuoli SV, Oggioni M, Dunning Hotopp JC, Hu FZ, Riley DR, et al: Structure and dynamics of the pan-genome of Streptococcus pneumoniae and closely related species. Genome Biol 2010, 11(10):R107.

35. Touchon M, Hoede C, Tenaillon O, Barbe V, Baeriswyl S, Bidet P, Bingen $E_{\text {, }}$ Bonacorsi S, Bouchier C, Bouvet $\mathrm{O}$, et al: Organised genome dynamics in the Escherichia coli species results in highly diverse adaptive paths. PLoS Genet 2009, 5(1):e1000344.

36. Severi E, Hood DW, Thomas GH: Sialic acid utilization by bacterial pathogens. Microbiology 2007, 153(Pt 9):2817-2822.

37. Iversen C, Forsythe S: Risk profile of Enterobacter sakazakii, an emergent pathogen associated with infant milk formula. Trends in Food Science \&amp Technology 2003, 14(11):443-454.

38. Lehner A, Riedel K, Rattei T, Ruepp A, Frishman D, Breeuwer P, Diep B, Eberl L, Stephan R: Molecular characterization of the alpha-glucosidase activity in Enterobacter sakazakii reveals the presence of a putative gene cluster for palatinose metabolism. Syst Appl Microbiol 2006, 29(8):609-625.

39. Hashimi SM, Wall MK, Smith AB, Maxwell A, Birch RG: The phytotoxin albicidin is a novel inhibitor of DNA gyrase. Antimicrob Agents Chemother 2007, 51(1):181-187.

40. Gibson DL, White AP, Snyder SD, Martin S, Heiss C, Azadi P, Surette M, Kay WW: Salmonella produces an O-antigen capsule regulated by AgfD and important for environmental persistence. J Bacteriol 2006, 188(22):7722-7730

41. White AP, Gibson DL, Kim W, Kay WW, Surette MG: Thin aggregative fimbriae and cellulose enhance long-term survival and persistence of Salmonella. J Bacteriol 2006, 188(9):3219-3227. 
42. Fisher S, Barry A, Abreu J, Minie B, Nolan J, Delorey TM, Young G, Fennell TJ, Allen $A$, Ambrogio $L$, et al: A scalable, fully automated process for construction of sequence-ready human exome targeted capture libraries. Genome Biol 2011, 12(1):R1.

43. Aziz RK, Bartels D, Best AA, DeJongh M, Disz T, Edwards RA, Formsma K, Gerdes S, Glass EM, Kubal M, et al: The RAST Server: rapid annotations using subsystems technology. BMC Genomics 2008, 9:75.

44. Chun J, Grim CJ, Hasan NA, Lee JH, Choi SY, Haley BJ, Taviani E, Jeon YS, Kim DW, Lee JH, et al: Comparative genomics reveals mechanism for short-term and long-term clonal transitions in pandemic Vibrio cholerae. Proc Natl Acad Sci USA 2009, 106(36):15442-15447.

45. Grim CJ, Hasan NA, Taviani E, Haley B, Chun J, Brettin TS, Bruce DC, Detter $J C$, Han CS, Chertkov O, et al: Genome sequence of hybrid Vibrio cholerae O1 MJ-1236, B-33, and CIRS101 and comparative genomics with V. cholerae. J Bacteriol 2010, 192(13):3524-3533.

46. Grim CJ, Kozlova EV, Sha J, Fitts EC, Van Lier CJ, Kirtley ML, Joseph SJ, Read TD, Burd EM, Tall BD, et al: Characterization of Aeromonas hydrophila wound pathotypes by comparative genomic and functional analyses of virulence genes. mBio. doi:10.1128/mBio.00064-13.

47. Haley BJ, Grim CJ, Hasan NA, Choi SY, Chun J, Brettin TS, Bruce DC, Challacombe JF, Detter JC, Han CS, et al: Comparative genomic analysis reveals evidence of two novel Vibrio species closely related to $\mathrm{V}$. cholerae. BMC Microbiol 2010, 10:154.

48. Overbeek R, Begley T, Butler RM, Choudhuri JV, Chuang HY, Cohoon M, de Crecy-Lagard V, Diaz N, Disz T, Edwards R, et al: The subsystems approach to genome annotation and its use in the project to annotate 1000 genomes. Nucleic Acids Res 2005, 33(17):5691-5702.

49. Kurtz S, Phillippy A, Delcher AL, Smoot M, Shumway M, Antonescu C, Salzberg SL: Versatile and open software for comparing large genomes. Genome Biol 2004, 5(2):R12.

50. Goris J, Konstantinidis KT, Klappenbach JA, Coenye T, Vandamme P, Tiedje JM: DNA-DNA hybridization values and their relationship to wholegenome sequence similarities. Int J Syst Evol Microbiol 2007, 57(Pt 1):81-91.

51. Richter M, Rossello-Mora R: Shifting the genomic gold standard for the prokaryotic species definition. Proc Natl Acad Sci USA 2009, 106(45):1912619131.

52. Hasan NA, Grim CJ, Haley BJ, Chun J, Alam M, Taviani E, Hoq M, Munk AC, Saunders E, Brettin TS, et al: Comparative genomics of clinical and environmental Vibrio mimicus. Proc Natl Acad Sci USA 2010, 107(49): 21134-21139.

53. Tamura K, Peterson D, Peterson N, Stecher G, Nei M, Kumar S: MEGA5: molecular evolutionary genetics analysis using maximum likelihood, evolutionary distance, and maximum parsimony methods. Mol Biol Evol 2011, 28(10):2731-2739.

doi:10.1186/1471-2164-14-366

Cite this article as: Grim et al:: Pan-genome analysis of the emerging foodborne pathogen Cronobacter spp. suggests a species-level bidirectional divergence driven by niche adaptation. BMC Genomics 2013 14:366.

\section{Submit your next manuscript to BioMed Central and take full advantage of:}

- Convenient online submission

- Thorough peer review

- No space constraints or color figure charges

- Immediate publication on acceptance

- Inclusion in PubMed, CAS, Scopus and Google Scholar

- Research which is freely available for redistribution 